\title{
Ultrasonic Evaluation of High-Early Strength Concrete Subjected to Isothermal Curing
}

\author{
Patrick Junther R. Sazon, Oscar Victor M. Antonio, Jr., Marlon L. de la Cruz \\ Institute of Civil Engineering, University of the Philippines \\ Diliman, Quezon City 1101, Metro Manila, Philippines \\ pjrsazon@yahoo.com.ph; omantonio@up.edu.ph; mldc79@yahoo.com
}

\begin{abstract}
High early-strength concrete are commonly used for reinforced bulk/mass concrete foundations of structures. Based on the temperature measurements for an actual project, it was found out that even after implementing the necessary countermeasures, the recorded temperatures exceeded the threshold values recommended by the American Concrete Institute specifications. Thus, these mass concrete are usually subjected to isothermal curing. The study aims to evaluate high-early strength concrete subjected isothermal curing using linear and nonlinear ultrasonics. These ultrasonic evaluation techniques include ultrasonic pulse velocity test, scaling subtraction method, and harmonic generation method. Ultrasonic tests were conducted to concrete specimens before and after subjecting them to compression loading using the universal testing machine. Comparison between the results of normally cured specimens and isothermally cured specimens were made. Test results showed that the damages in the isothermally cured specimens were more apparent than that in the normally cured specimens. Therefore, it was proven that control measures are required to prevent or reduce the progression of damage due to isothermal curing.
\end{abstract}

Keywords: Ultrasonic Evaluation, High-Early Strength Concrete, Mass Concrete, Isothermal Curing.

\section{Introduction}

The actual condition of the mass concrete during the curing process is different from the conditions for the representative test samples specified by the standards (i.e. ASTM C31 and ASTM C39) since the mass concrete is exposed to very high heat of hydration. For instance, actual temperature monitoring for a poured mat foundation of a turbinegenerator had shown extremely high temperature readings exceeding $100^{\circ} \mathrm{C}$ [1], which is way beyond the temperature limit specified by the American Concrete Institute (ACI) and Portland Cement Association (PCA). High-early strength concrete when utilized in concrete pouring of bulk foundations are usually designed with the use of high performance/high strength concrete admixture, which is characterized by a low water to cement ratio. As a consequence, self-desiccation takes place leading to shrinkage of concrete paste. The moisture is lost either through evaporation (drying shrinkage) or internal reactions (autogenous shrinkage). But probable generation of cracks is minimized by the presence of steel reinforcement.

Linear ultrasonic methods are associated with mono-frequency equipment that measures variations in the amplitude and phase of the input signal caused by scattering due to defects/anomalies. On the other hand, nonlinear ultrasonic methods are associated with the distortion of signals, such as frequency variation, due to micro- and macro-scale defects. The study aims to know the effects of thermal conditions on the strength of and damage in mass concrete through linear ultrasonic method (ultrasonic pulse velocity test) and nonlinear ultrasonic methods (scaling subtraction and harmonic generation methods). This will be done through evaluating mass concrete samples damage due to compressive loading alone and compressive loading plus thermal loading. The extent and scope of this work shall be specifically for the sampling and testing of 5,000psi (35MPa) at 3-day high-early strength concrete design mix. Available actual temperature records at the time of this study only apply to this specific age of concrete. Furthermore, water to cement ratio shall be lower than 0.32 , which is within the range for which isothermal (chemical reaction) curing is expected to occur. The size of concrete cylinder samples were reduced proportionately to $50 \mathrm{~mm}$ diameter $\mathrm{x} 100 \mathrm{~mm}$ height since these will be enclosed and sealed in flexible rubber membranes and then subjected to isothermal curing. Evaluation of the test samples was conducted after $1,3,5,7,14,21,28$, and 56 days of curing. The evaluation of strength is limited to the compressive yield strength of the sample since the ultrasonic evaluation will need an intact flat surface after compression. 


\section{Methodology \\ 2.1. Materials}

The temperature data records were taken from an actual concrete pouring for a turbine-generator and chimney flue foundation, elevated superstructure of turbine generator. Based from this actual temperature monitoring readings taken at different parts of the structure, the temperature data sets for the turbine-generator mat foundation shall serve as the reference temperature reading on subsequent simulated monitoring covered by this work. Correspondingly, the concrete design mix with ideal design strength of 5,000 Psi (35 MPa) at 3 days was adopted with relative adjustments on material proportions as recommended by ACI 211.1; and based from the actual quality test results of major constituent materials including cement, fine and coarse aggregates, and admixture.

The concrete constituent materials, testing equipment and laboratory apparatus including laboratory and concrete mixing facilities were sourced and arranged with Tokwing Infinite Batching Plant situated at Mindanao Avenue, Quezon City, Philippines. The conduct of materials and concrete sampling was directly held at the confines of laboratory premises since concrete samples were expected to have early-strength development and was according to ACI 211.1 [2]. ASTM C172 [3] shall be applied in selecting appropriate sample size through wet sieving to obtain the desired ratio and proportion relative to the size of concrete cylinder sample $(57 \mathrm{~mm})$. Provision for needed thermal bath for membrane method curing measurement was set-up and installed prior to concrete sampling. Thermostat equipment controller has reading accuracy of $0.1^{\circ} \mathrm{C}$ with regular readings encoded once concrete cylinder samples were already in-place.

\subsection{Curing}

Two groups of concrete specimens were used in the study. The first group was subjected to normal curing based on standard practices while the second group was subjected to isothermal curing. There were 28 specimens for each group; a total of 56 mass concrete specimens were used. A digital thermostat controller was operated with attached thermocouple device submerged at the center of the paraffin/mineral oil bath. This device ensures that the actual temperature will simulate the encoded reference temperature data. Once the concrete cylinder samples were tightly wrapped in flexible rubber membrane they were immersed in the thermal bath. Simultaneously undertaken with this procedure is the laboratory curing of similar identical samples prepared as per ASTM C31 [4]. Each representative samples (minimum set of 3 concrete cylinder) were tested at specified 1,2,3,7,14, 21, 28 and 56-days curing period to determine respective compressive strength of concrete.

\subsection{Ultrasonic Testing}

The study used the PUNDITLAB for the ultrasonic time domain data acquisition. For the linear ultrasonic test, a 150 $\mathrm{kHz}$ transducer was used as the transmitter and another $150 \mathrm{kHz}$ transducer was used as the receiver. For the nonlinear ultrasonic tests, a $54 \mathrm{kHz}$ transducer was used as the transmitter and a $150 \mathrm{kHz}$ transducer was used as the receiver. Petroleum jelly was used as a couplant to provide sufficient conductivity for the ultrasonic signals. After each curing age, the isothermally and normally cured concrete specimens were subjected to linear and nonlinear ultrasonic tests before and after they were subjected to compression test. A Universal Testing Machine (UTM) was used to subject the test specimens to about $80-85 \%$ of their compression strengths. The pulse velocities were obtained directly from Punditlink, the software available from PUNDITLAB. The pulse velocities were tabulated and graphed against the curing age. The time domain data from both linear and nonlinear tests/readings were converted to frequency domain using Fast Fourier Transformation.

For the scaling subtraction method, the nonlinear waveform data before the compression loading were subtracted from the waveform data after the compression loading. The absolute value of the maximum value in the SSM signal was obtained to get the value of the SSM indicator, which quantifies the concrete damage. The greater the value of the SSM indicator signifies greater concrete damage. The computed SSM indicators were graphed against the curing age.

For the harmonic generation method, the frequency data from the nonlinear tests/readings after compression were used. The fundamental frequency, second harmonic, and third harmonic were observed at $20 \mathrm{kHz}, 40 \mathrm{kHz}$, and $60 \mathrm{kHz}$, respectively. The amplitudes at these frequencies were obtained and tabulated to compute for the second and third harmonic ratios. These harmonic ratios also quantify concrete damage wherein a large value of the ratio signifies the presence of concrete damage. The harmonic ratios are also graphed against the curing age. 


\section{Results}

It was observed that the pulse velocities of the isothermal specimens before and after compression have the least values during the curing age of 3 (day 3). This is due to the fact that the isothermal specimens were subjected to the hottest temperature of around $106{ }^{\circ} \mathrm{C}$ during day 3 . The small velocity values indicate that the isothermal specimens at day 3 had the most evident damage from the previous curing age (day 1). At day 7, the pulse velocities increased. This may be the effect of the production of C-S-H gels (Calcium-Silicate-Hydrate gels) from the use of fly ash. These chemical products may have occupied the discontinuities made from the micro-cracks. After day 7, the velocities slightly decrease which show a slight increase in the isothermal specimen damage. For the normal specimens, the pulse velocity values slowly increase as the curing age lengthens. The differences between the pulse velocities before and after compression were obtained as shown in Figure 1. The difference values of the isothermal specimens are greater than that of the normal specimens that indicates that the isothermal specimens are more damaged than the normal specimens. The trend shows that there is less addition of damage or discontinuities as curing age progresses.

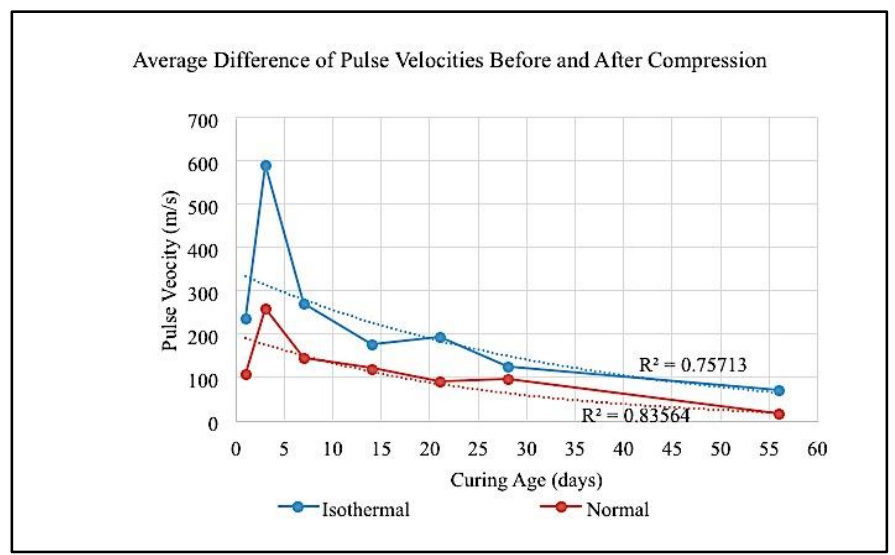

Fig. 1: Average difference of pulse velocities before and after compression loading.

Scaling Subtraction Method uses the SSM indicator to quantify damage wherein the greater the value of the SSM indicator means the greater the presence of concrete damage. In Figure 2, the SSM indicator of the isothermal specimens are greater than that of the normal specimens at the early stages which means that the isothermal specimens are more damaged than the normal specimens at early stages. The decreasing trend after a peaking SSM indicator signifies that the isothermal specimens experience the clapping mechanism of the micro-cracks. The micro-cracks create low-quality layer or crack-like (relatively larger cracks) discontinuities that are closed or collapse when the compressive loadings are applied. Thus, the slight increase in damage is not detected in the later stages.

The harmonic generation method uses harmonic ratio to quantify the concrete damage, such that the higher the ratio is the greater the concrete damage. As shown in Figure 3, the isothermal specimens are more damaged than the normal specimens at early ages. Then, the values slightly decreased and fluctuated until around day 27. Around day 27, the temperature stabilizes and becomes almost similar to the normal specimens' curing temperature. Since the isothermal curing temperature is now similar to the normal curing temperature, the isothermal specimens' ratio trend follows that of the normal specimens' increasing trend. Nevertheless, the isothermal specimens were already more damaged than the normal specimens at early stages.

It is important to note that the best-fit curves for each graph were chosen based on the highest coefficient of determination $\left(\mathrm{R}^{2}\right)$. This was done in order to compare the general trends and to show how erratic the graphs were, particularly for the nonlinear ultrasonic results, thus leading to small values of $\mathrm{R}^{2}$. 


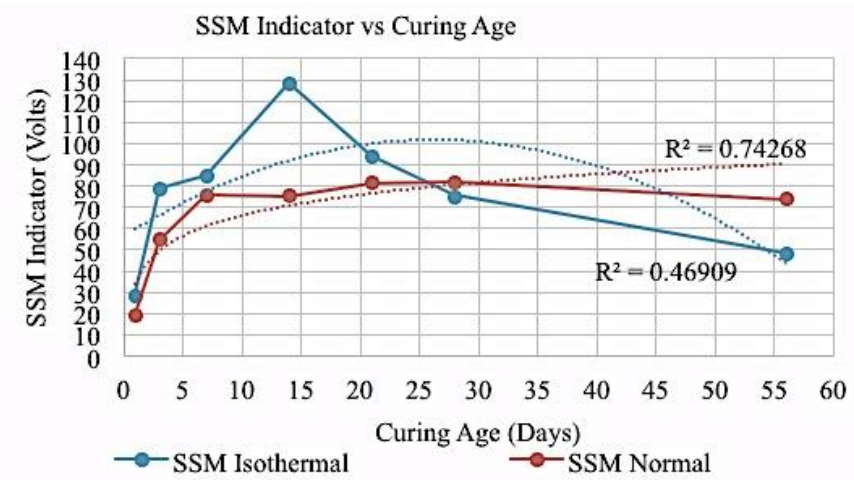

Fig. 2: Average SSM indicator versus curing age graph.

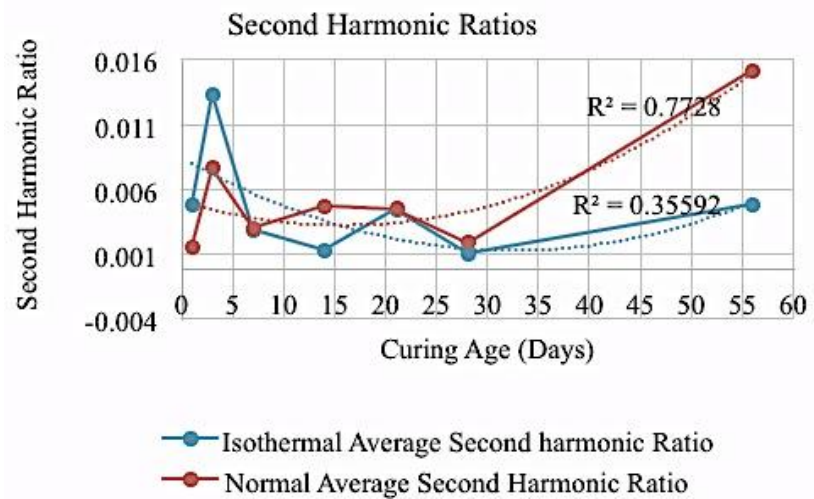

Fig. 3: Average second harmonic ratio values versus curing age.

\section{Conclusion}

All ultrasonic methods of nondestructive testing produced similar results wherein the isothermal specimens were more damaged than the normal specimens. However, it is observed that the nonlinear ultrasonic methods were more efficient than linear ultrasonic method as they provide more information on the progression of concrete damage. An example of the additional information was the detection of the clapping mechanism of discontinuities that was detected by the Scaling Subtraction Method, but not for Harmonic Generation Method. Nevertheless, both are good methods since they can detect micro-cracks as observed by the sensitivity of the values. The slightly fluctuating values are indications of the sensitivity of the methods. It was good to use nonlinear ultrasonic methods in monitoring concrete damage for the quality control of the mass concrete structure, but it is better to use all available ultrasonic methods for a more detailed and credible monitoring process.

\section{References}

[1] M. D. Cruz and O. V. M. Antonio, "Effects of isothermal curing on compressive strength of high-early strength concrete," in Proceedings of the $2^{\text {nd }}$ World Congress on Civil, Structural, and Environmental Engineering (CSEE'17), Barcelona, Spain, 2017.

[2] American Concrete Institute; ACI Committee 211, Standard Practice for Selecting Proportions for Normal, Heavyweight, and Mass Concrete. ACI 211.1-91, 1991.

[3] American Concrete Institute; ACI Committee 207, Effect of Restraint, Volume Change, and Reinforcement on Cracking of Mass Concrete. ACI 207.2R-95, 1995.

[4] American Society for Testing and Materials (ASTM), Standard Practice for Making and Curing Concrete Test Specimens in the Field, ASTM C31/C31M-96, 1996.

[5] American Concrete Institute; ACI Committee 207, Guide to Mass Concrete, ACI 207.1R-05, 2006. 
[6] P. Antonaci, C. Gliozzi, and M. Scalerandi, "Monitoring evolution of compressive damage in concrete with linear and nonlinear ultrasonic methods, Cement and Concrete Research," vol. 40, no. 7, pp. 1106-1113, 2010.

[7] O. V. M. Antonio, S. Hirose, and A. Shah, "New trends for ultrasonic NDE for concrete: nonlinear ultrasonic evaluation and ultrasonic imaging by SAFT," in Proceedings of the $3^{\text {rd }}$ JSPS-DOST International Symposium on Environmental Engineering, Metro Manila, Philippines, 2009.

[8] Portland Cement Association, Design and Control of Concrete Mixtures-EB001, 15th ed, 2011.

[9] Portland Cement Association, "Ettringite Formation and the Performance of Concrete," Concrete Information, Journal, 2001. 